\title{
Prevalence of gastro-esophageal reflux in diabetic patients at a tertiary hospital in Central Saudi Arabia
}

FatimahM.AlTassan, MedicalStudent, SaadS.Al-Khowaiter, MD, HaneenE.Alsubki, MedicalStudent, Wateen A. Alhamoud, MedicalStudent, Ameera K. Niazi, Medical Student, Badr M. AlJarallah, MD, FRCP.

\begin{abstract}

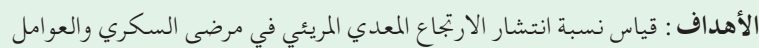

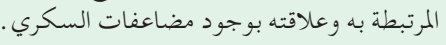

المنهجية : أجريت دراسة مقطعية عرضية لاستقصاء نسبة الارتجاع المعدي المريئي

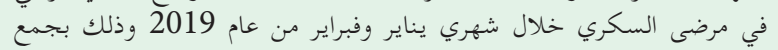

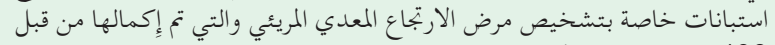

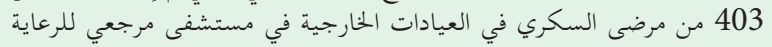

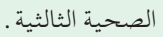

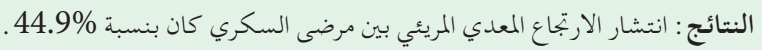

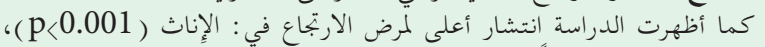

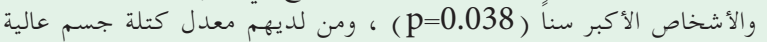

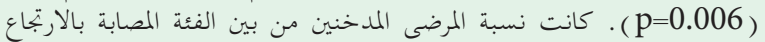

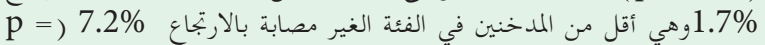

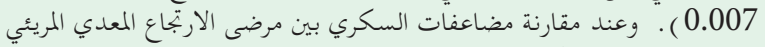

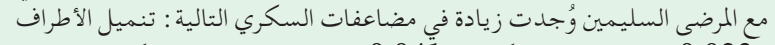

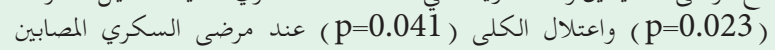

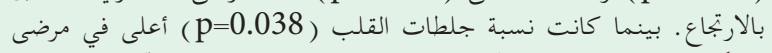

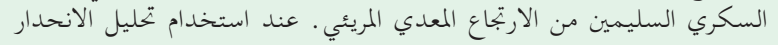

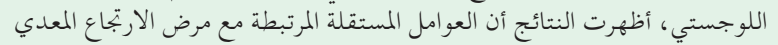

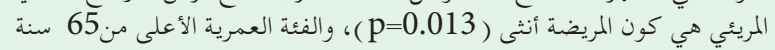
. ( $\mathrm{p}=0.007)$

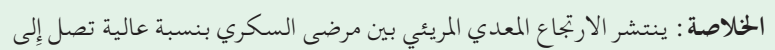

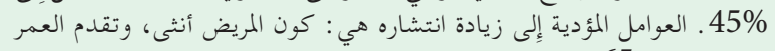

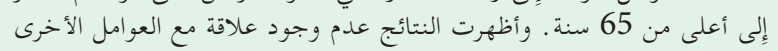

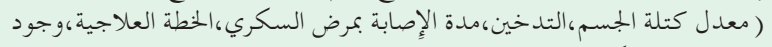

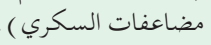

Objectives: To estimate the prevalence of gastroesophageal reflux disease (GERD) among diabetic patients and to investigate GERD's potential association with diabetic complications, and patients' sociodemographic and clinical characteristics.

Methods: This cross-sectional study used the GERD questionnaire (GerdQ) in 403 diabetic patients attending the outpatient clinics at King Khalid University Hospital, King Saud University Medical City, King Saud University; a tertiary hospital in Riyadh, Saudi Arabia, between
January and February 2019. On the basis of a cutoffGerdQ scoreof 8, wedistinguishedGERDand non-GERDgroups.

Results: Gastro-esophageal reflux disease prevalence was $44.9 \%$. Of the diabetic patients with GERD, $76.8 \%$ were female $(p<0.001)$. Gastro-esophageal reflux disease patients were older (mean age: 55.27, $p=0.038$ ) and had a slightly higher body mass index (BMI) than non-GERD (32.04 versus, $30.20 p=0.006$ ), respectively. Smokers in the GERD group were $1.7 \%$ versus $7.2 \%$ in the nonGERD group $(p=0.007)$. Peripheral numbness $(p=0.023)$ and nephropathy $(p=0.041)$ were more prevalent in patients with GERD, while myocardial infarction was more prevalent in non-GERD subjects $(p=0.038)$. On multi variable analysis, the only independent GERD risk factors were female gender $(p=0.013)$ and age $>65$ years $(p=0.007)$.

Conclusion: Gastro-esophageal reflux disease prevalence in diabetic patients was $45 \%$. Diabetic patients with GERD were more often female and older $>65$ years. None of the other tested factors (BMI, smoking status, diabetes mellitus duration, therapeutic plan, or diabetic complications) showed significant difference between GERD and non-GERD groups.

Keywords: diabetes mellitus, gastroesophageal reflux, diabetes mellitus/complications, gastrointestinal motility, Saudi Arabia/epidemiology

Saudi Med J 2020; Vol. 41 (2): 151-156 doi: 10.15537/smj.2020.2.24844

From the College of Medicine (AlTassan, Alsubki, Alhamoud, Niazi); from the Division of Gastroenterology (Al-Khowaiter), King Saud University Medical City, Riyadh, and from the Division of Hepatology and Gastroenterology (AlJarallah), Qassim University Medical City, Qassim, Kingdom of Saudi Arabia.

Received 9th October 2019. Accepted 12th December 2019.

Address correspondence and reprint request to: Dr. Fatimah $M$. AlTassan, College of Medicine, King Saud University Medical City, Riyadh, Kingdom of Saudi Arabia. E-mail: Faltassan8@gmail.com ORCID ID: https://orcid.org/0000-0002-2207-5703 
$\mathrm{D}$ iabetes mellitus (DM) is a leading cause of several gastrointestinal motility disorders, that includes gastro-esophageal reflux disease (GERD) and gastroparesis. ${ }^{1,2}$ Obesity is a common factor in type 2 DM patients. The mechanism of GERD development in diabetic patients is multifactorial and mainly directed by obesity and gastro-esophageal dysmotility that together or alone can result in GERD. The presence of obesity in those patients creates a high intraabdominal pressure that may result in hiatal herniation which is a direct anatomical cause of reduction of lower esophageal sphincter tone causing acid reflux. The other pathway of GERD development is caused by gastroparesis and esophageal dysmotility resulting from neuropathy that complicates hyperglycemia and DM. Furthermore, the presence of diabetes or obesity causes hormonal dysregulation of ghrelin and motilin. This hormonal dysregulation also contributes to gastroparesis and esophageal dysmotility. ${ }^{1}$ In addition to carrying the risk of Barret's esophagus and esophageal adenocarcinoma, GERD negatively effects patients' living conditions, productivity, and sleep. ${ }^{3,4}$ Nevertheless, modification of lifestyle habits such as reducing meal size and controlling blood sugar levels can prevent and treat gastrointestinal complications of DM. ${ }^{2}$

The prevalence of type $2 \mathrm{DM}$ in the Kingdom of Saudi Arabia (KSA) is $32.8 \% .^{5}$ The incidence of new cases of type one DM among age group of 0-14 years in KSA in 2019 is 31.4 per 100,000 population per year. $^{6}$

Gastro-esophageal reflux disease is also common in the general population of KSA, with a prevalence varying between $28.7-45.4 \% .^{7,8}$ Several studies in other countries have reported more GERD prevalence in patients with DM than in the general population. ${ }^{9,10}$

In this study, we aimed to estimate the prevalence of symptomatic GERD in diabetic patients and to investigate GERD's potential associations with diabetic microvascular and macrovascular complications, and with patients' sociodemographic and clinical characteristics.

Methods. We conducted a PubMed search using the medical subject heading terms: gastroesophageal reflux, diabetes mellitus, epidemiology, diabetes mellitus/

Disclosure. This study was funded by the Deanship of Scientific Research at King Saud University, Riyadh, Kingdom of Saudi Arabia, through the Undergraduate Student's Research Support Program, Project No. (URSP-4-19-71). complications, gastrointestinal motility, heartburn, and Saudi Arabia/epidemiology as well as keyword searches of Saudi Arabia, prevalence, GERD, diabetic. We also manually searched reference citations in the identified articles. We reviewed studies in the English language only.

We conducted this cross-sectional study in the outpatient clinics of King Khalid University Hospital, King Saud University Medical City, King Saud University; a tertiary hospital in Riyadh, KSA, between January and February 2019. The study was carried out in accordance with the Declaration of Helsinki and approved by the Institutional Review Board of College of Medicine, King Saud University, Riyadh, KSA.

The inclusion criteria was self-report of being previously diagnosed with type 1 or 2 DM. Patients who were not diabetic or had a DM type other than type 1 or 2 were not invited to participate.

We collected data through a questionnaire that was completed during an interview. We explained the purpose of the study to all patients and included those who agreed to participate. We assured participants' anonymity by assigning each participant a code number for the purpose of data analysis only.

The questionnaire asked about gender, age, height, weight, smoking status, duration of diabetes, the therapeutic plan for diabetes control (diet, exercise, oral hypoglycemic agents [OHA], or insulin), and any history of micro- or macrovascular complications (numbness in extremities as a sign of peripheral neuropathy, retinopathy, nephropathy or albuminuria or proteinuria, hypertension [HTN], coronary artery disease $[\mathrm{CAD}]$, myocardial infarction $[\mathrm{MI}]$, stroke, or limb amputations). The last part was the GERD questionnaire (GerdQ) translated into Arabic. The Arabic version of GerdQ was adapted from 2 similar studies carried out in the country. ${ }^{7,8}$

The GERD questionnaire, which has been shown to have a sensitivity of $65 \%$ and a specificity of $71 \%$, is a 6-item questionnaire wherein patients were asked to recall the frequency of specific GERD symptoms during the past week. Based on the frequency, each of the 6 symptoms will account for one point on a scale of $0-3$. The obtained score will range between $0-12$, and GERD is diagnosed on the basis of a score of 8 or higher. $^{11}$

Before the study, we conducted a pilot trial on 19 diabetic patients by interviewing them face-to-face to ensure their understanding of the questions and to calculate the study sample size using the estimated proportion from the pilot study. The prevalence of GERD symptoms among the pilot study patients was $52.6 \%$. 
We calculated the minimum sample size to be 384 by applying the following formula:

$$
\mathrm{n}=\frac{\mathrm{P}(1-\mathrm{P}) \times \mathrm{Z}_{1-\alpha}{ }^{2}}{\mathrm{~d}^{2}}
$$

assuming a prevalence of $52 \%$ from the pilot study, at a $5 \%$ error rate and $95 \%$ confidence interval. We recruited 403 consecutive patients from the outpatient clinics and who reported that they had type 1 or 2 DM.

Statistical analysis. We analyzed the data using Statistical Package for Social Studies for Windows, version 22 (IBM Corp, Armonk, NY, USA). We used descriptive statistics (numbers, percentages, mean, and standard deviation [SD]) to describe the study's outcome variables. We used the Fisher's exact and Chi-square tests for categorical variables and the t-test for continuous variables. Univariable and multivariable logistic regression analyses were performed to define which risk factors were most likely to be associated with prevalent GERD. A $p$-value of $<0.05$ was used to define the statistical significance of the results. We used Cronbach's alpha coefficient to test the internal consistency of the Arabic GerdQ items.

Results. The Cronbach's alpha was scored at 0.848 for overall items which reflects good reliability and internal consistency of the items in the Arabic GerdQ (Table 1).

Sociodemographic characteristics are shown in Table 2. Among the 403 self-reported diabetic patients, $126(31.3 \%)$ were male and 277 (68.7\%) female. The mean $\pm S D$ age of all study participants was $53.70 \pm 13.95$ years. The mean \pm SD BMI was $31.02 \pm 6.65$. Non-smokers and ex-smokers formed the vast majority of patients ( $n=384,95.3 \%)$, with current smokers constitute 19 patients (4.7\%).

Based on the results of the GerdQ, the subjects were divided into 2 groups: GERD (181 subjects)

Table 1 - Reliability analysis of the overall questionnaire.

\begin{tabular}{lcccc}
\hline Variables & $\begin{array}{c}\text { Scale } \\
\text { mean* }\end{array}$ & $\begin{array}{c}\text { Scale } \\
\text { variance* }\end{array}$ & $\begin{array}{c}\text { Cronbach's } \\
\text { alpha* }\end{array}$ & $\begin{array}{c}\text { Corrected } \\
\text { item-total } \\
\text { correlation }\end{array}$ \\
\hline Heartburn & 8.95 & 18.16 & 0.82 & 0.67 \\
Regurgitation & 9.13 & 17.97 & 0.80 & 0.74 \\
Epigastric pain & 9.08 & 18.28 & 0.82 & 0.66 \\
Nausea & 9.27 & 18.78 & 0.82 & 0.64 \\
Sleeping difficulty & 9.42 & 19.62 & 0.83 & 0.61 \\
$\begin{array}{l}\text { GERD } \\
\text { medications }\end{array}$ & 8.99 & 18.60 & 0.85 & 0.50 \\
\hline
\end{tabular}

*if item deleted, GERD: gastro-esophageal reflux disease and non-GERD (222 subjects), accounting for a GERD prevalence of $44.9 \%$. Table 3 shows the comparison between the characteristics of the 2 groups. Gastroesophageal reflux disease was higher among women $(p<0.001)$, and among older individuals, mean \pm SD age was $55.27 \pm 11.93$ years in the GERD compared to $52.43 \pm 15.32$ years in the non-GERD subjects $(p=0.038)$. Furthermore, BMI was slightly different between the 2 groups; the mean \pm SD BMI was 32.04 \pm 6.6 in the GERD group and $30.20 \pm 6.6$ in patients without GERD $(p=0.006)$. Smoking was negatively correlated with GERD: smokers accounted for $1.7 \%$ in the GERD and $7.2 \%$ in the non-GERD groups, $(p=0.007)$. The prevalence of reported peripheral numbness nephropathy was higher in the GERD group than in patients without GERD, while MI was more prevalent among non-GERD subjects (Table 4). There was no difference between GERD and non-GERD patients with regard to the duration of their $\mathrm{DM}$ and therapeutic plans, as well as the frequency of HTN, albuminuria, amputation, stroke, CAD, and retinopathy..

On univariate logistic regression, significant risk factors associated with GERD were found to be female gender $(p=0.002)$, age $>65$ years $(p=0.005)$, obesity $(p=0.009)$, peripheral numbness $(p=0.024)$, and

Table 2 - Baseline characteristics of diabetic patients ( $\mathrm{N}=403)$.

\begin{tabular}{lc}
\hline Characteristics & Mean \pm SD \\
\hline Gender (male/female), $\mathrm{n}(\%)$ & $126(31.3) / 277(68.7)$ \\
Age & $53.70 \pm 13.95$ \\
Weight $(\mathrm{kg})$ & $80.17 \pm 17.13$ \\
Height $(\mathrm{cm})$ & $160.96 \pm 9.92$ \\
Body mass index & $31.02 \pm 6.65$ \\
Smoking status, $\boldsymbol{n}(\%)$ & \\
Smoker & $19(4.7)$ \\
Non-smoker or ex-smoker & $384(95.3)$ \\
\hline
\end{tabular}

Table 3 - Comparison of patient characteristics between diabetic patients with and without GERD $(\mathrm{N}=403)$.

\begin{tabular}{lccc}
\hline Characteristics & $\begin{array}{c}\text { GERD } \\
(\mathbf{n}=181)\end{array}$ & $\begin{array}{c}\text { Non-GERD } \\
(\mathbf{n}=222)\end{array}$ & $P$-value \\
\hline Male, $\mathrm{n}(\%)$ & $42(23.2)$ & $84(37.8)$ & $<0.001$ \\
Female, $\mathrm{n}(\%)$ & $139(76.8)$ & $138(62.2)$ & \\
Age $($ mean \pm SD) & $55.27 \pm 11.93$ & $52.43 \pm 15.32$ & 0.038 \\
Weight $($ mean \pm SD) & $81.71 \pm 16.75$ & $78.92 \pm 17.36$ & 0.106 \\
Height $($ mean \pm SD) & $159.88 \pm 9.38$ & $161.84 \pm 10.28$ & 0.051 \\
BMI (mean \pm SD) & $32.04 \pm 6.60$ & $30.20 \pm 6.60$ & 0.006 \\
$\begin{array}{l}\text { Smoking status, } n(\%) \\
\text { Smoker }\end{array}$ & $3(1.7)$ & $16(7.2)$ & \\
$\quad \begin{array}{l}\text { Non-smoker or ex- } \\
\text { smoker }\end{array}$ & $178(98.3)$ & $206(92.8)$ & 0.007 \\
\hline \multicolumn{4}{l}{ GERD: gastroesophageal reflux disease, BMI: body mass index } \\
\hline
\end{tabular}


Table 4 - Comparison of clinical characteristics between gastroesophageal reflux disease and non-GERD diabetic patients $(\mathrm{N}=403)$.

\begin{tabular}{|c|c|c|c|}
\hline Characteristics & $\begin{array}{c}\text { GERD } \\
(n=181)\end{array}$ & $\begin{array}{c}\text { Non-GERD } \\
(\mathrm{n}=222)\end{array}$ & $P$-value \\
\hline \multicolumn{4}{|c|}{ Duration of diabetes mellitus (years) } \\
\hline$<5$ & $47(26.0)$ & $56(25.2)$ & \\
\hline $5-9$ & $36(19.9)$ & $42(18.9)$ & \\
\hline $10-14$ & $33(18.2)$ & $39(17.6)$ & 0.795 \\
\hline $15-19$ & $26(14.4)$ & $26(11.7)$ & \\
\hline$\geq 20$ & $39(21.5)$ & $59(26.6)$ & \\
\hline \multicolumn{4}{|l|}{ Therapeutic plan } \\
\hline Exercise & $44(24.3)$ & $61(27.5)$ & 0.471 \\
\hline Diet therapy & $75(41.4)$ & $86(38.7)$ & 0.582 \\
\hline OHA & $146(80.7)$ & $162(73.0)$ & 0.070 \\
\hline Insulin therapy & $79(43.6)$ & $110(49.5)$ & 0.238 \\
\hline \multicolumn{4}{|l|}{ Diabetic complications } \\
\hline Peripheral numbness & $125(69.1)$ & $129(58.1)$ & 0.023 \\
\hline Hypertension & $89(49.2)$ & $97(43.7)$ & 0.273 \\
\hline Nephropathy & $22(12.2)$ & $14 \quad(6.3)$ & 0.041 \\
\hline Albuminuria or proteinuria & $20(11.0)$ & $31(14.0)$ & 0.231 \\
\hline Amputation & $3(1.7)$ & $1 \quad(0.5)$ & 0.239 \\
\hline Stroke & $5(2.8)$ & $3(1.4)$ & 0.257 \\
\hline Coronary artery disease & $23(12.7)$ & $19(8.6)$ & 0.175 \\
\hline Myocardial infarction & $4 \quad(2.2)$ & $14 \quad(6.3)$ & 0.038 \\
\hline Retinopathy & $50(27.6)$ & $63(28.4)$ & 0.867 \\
\hline
\end{tabular}

nephropathy ( $p=0.044)$ (Table 5). Whereas smoking was negatively correlated with GERD (odds ratio $=0.217$, $p=0.017$ ).

After multivariate adjustment, the only variables found to be independently associated with higher GERD prevalence were female gender $(p=0.013)$ and age $>65$ years $(p=0.007)$ (Table 6$)$.

Discussion. We investigated GERD prevalence in patients with DM in relation with gender, age, BMI, smoking status, duration of diabetes, the different therapeutic plans such as diet, exercise, OHA, or insulin, and the presence of peripheral numbness, neuropathy, retinopathy, nephropathy, albuminuria, HTN, CAD, MI, stroke, or limb amputations.

In many countries, GERD has been reported to be more prevalent among diabetic patients than the general population. ${ }^{9,10}$ In China, patients with DM were found to have a prevalence of GERD that is 3 times higher compared to the general population. ${ }^{10}$ In Turkey, the estimated GERD prevalence in DM patients was $68 \% .^{12}$ A meta-analysis of 9 studies from Asian and Western regions reported that DM and GERD were significantly associated. However, most of these studies were cross-sectional; thus, a causal relationship could
Table 5 - Univariate logistic regression for risk factors of GERD.

\begin{tabular}{|c|c|c|c|c|}
\hline \multirow[t]{2}{*}{ Risk factor } & \multirow[t]{2}{*}{ OR } & \multicolumn{2}{|c|}{$95 \% \mathrm{CI}$} & \multirow[t]{2}{*}{$P$-value } \\
\hline & & Lower & Upper & \\
\hline \multicolumn{5}{|l|}{ Gender } \\
\hline Female & 2.01 & 1.30 & 3.12 & $0.002^{*}$ \\
\hline Male $^{\dagger}$ & 1.00 & & & \\
\hline \multicolumn{5}{|l|}{ Age } \\
\hline$<45^{\dagger}$ & 1.00 & & & \\
\hline $45-65$ & 1.63 & 0.96 & 2.77 & 0.071 \\
\hline$>65$ & 2.70 & 1.33 & 5.47 & $0.005^{*}$ \\
\hline \multicolumn{5}{|l|}{ Body mass index } \\
\hline $\mathrm{BMI}<25^{\dagger}$ & 1.00 & & & \\
\hline Overweight & 1.81 & 0.96 & 3.43 & 0.067 \\
\hline Obese & 2.19 & 1.21 & 3.95 & $0.009^{*}$ \\
\hline \multicolumn{5}{|l|}{ Smoking status } \\
\hline $\begin{array}{l}\text { Smoker } \\
\text { Non-smoker or ex-smoker }\end{array}$ & $\begin{array}{c}0.217 \\
1.00\end{array}$ & 0.062 & 0.757 & $0.017^{*}$ \\
\hline Numbness & 1.61 & 1.06 & 2.43 & $0.024^{*}$ \\
\hline Nephropathy & 2.06 & 1.02 & 4.14 & $0.044^{*}$ \\
\hline
\end{tabular}

Table 6 - Multivariate logistic regression for risk factors of GERD.

\begin{tabular}{|c|c|c|c|c|}
\hline \multirow[t]{2}{*}{ Risk factors } & \multirow[t]{2}{*}{ OR } & \multicolumn{2}{|c|}{$95 \% \mathrm{CI}$} & \multirow[t]{2}{*}{$P$-value } \\
\hline & & Lower & Upper & \\
\hline \multicolumn{5}{|l|}{ Gender } \\
\hline Female & 1.83 & 1.14 & 2.94 & $0.013^{*}$ \\
\hline Male $\dagger$ & 1.00 & & & \\
\hline \multicolumn{5}{|l|}{ Age } \\
\hline$<45 \dagger$ & 1.00 & & & \\
\hline $45-65$ & 1.48 & 0.85 & 2.57 & 0.162 \\
\hline$>65$ & 2.81 & 1.32 & 5.99 & $0.007^{*}$ \\
\hline \multicolumn{5}{|l|}{$B M I$} \\
\hline $\mathrm{BMI}<25 \dagger$ & 1.00 & & & \\
\hline Overweight & 1.65 & 0.85 & 3.19 & 0.140 \\
\hline Obese & 1.77 & 0.94 & 3.34 & 0.077 \\
\hline \multicolumn{5}{|l|}{ Smoking status } \\
\hline Smoker & 0.30 & 0.08 & 1.10 & 0.070 \\
\hline Non-smoker or ex-smoker $\dagger$ & 1.00 & & & \\
\hline Numbness & 1.46 & 0.94 & 2.28 & 0.094 \\
\hline Nephropathy & 1.50 & 0.71 & 3.17 & 0.285 \\
\hline
\end{tabular}

not be determined. ${ }^{13}$ In this study, the prevalence of GERD among diabetic patients was $44.9 \%$.

In the general population of KSA, GERD is associated with obesity and older age. ${ }^{8,14}$ The potential association between GERD and smoking among the KSA general population is controversial. One study reported no difference in the prevalence of GERD between smokers and non-smokers, whereas another study found that smoking is strongly associated with GERD. ${ }^{8,14}$ 
In our diabetic patients, the prevalence of GERD was significantly higher among older individuals and women. Also, GERD was most frequent among nonsmokers. However, it should be noted that women formed the majority of our sample, and women in KSA rarely smoke compared to men. ${ }^{13}$ This might explain the low percentage of smokers in the GERD group in our study.

Among diabetic patients, studies from many countries assessed upper gastrointestinal symptoms in relation with duration of DM, therapeutic plan, or different diabetic microvascular and macrovascular complications. ${ }^{16-18}$ A prospective study reported that lower esophageal sphincter pressure on manometry was the lowest in patients with longer duration of DM and that abdominal discomforts were more prevalent in patients with esophageal dysmotility than patients with delayed gastric emptying. ${ }^{16}$ A case-control reported higher prevalence of esophageal dysmotility in diabetic patients who have accompanying neuropathy. ${ }^{17}$ In Bangladesh, the reported prevalence of GERD among type 2 DM patients was $78.8 \%$, with HTN being a significantly associated risk factor. On the other hand, age, gender, weight, waist circumference, and duration of DM were similar between patients with GERD and patients without GERD. ${ }^{18}$

In this study, GERD subjects were more often female, older, obese, non-smokers, and had a higher prevalence of peripheral numbness and nephropathy on univariate analysis. However, after a multivariable adjustment, GERD was found to be significantly associated with female gender and age $>65$ years only.

Study limitations. The subjects were recruited from a single tertiary referral hospital. Thus, our findings cannot be generalized. However, since patients were referred to our hospital from all around the KSA, our study provides an overall fair idea regarding the diabetic population of KSA. Another limitation is that patients self-reported information about their history of being diagnosed with diabetic complications. Objective measures of these complications are needed in future research. Since this study was cross-sectional, causal relationships cannot be established.

In conclusion, the prevalence of GERD among diabetic patients was $45 \%$. That is similar to the prevalence among general population of KSA. Diabetic patients with GERD were more often female and older $>65$ years. None of the other tested factors (BMI, smoking status, DM duration, therapeutic plan, or diabetic complications) were different between GERD and non-GERD subjects.

Raising awareness about the high frequency of symptomatic GERD in diabetic patients as a complication of their DM is vital ensuring that physicians proactively identify and assess these symptoms and manage them optimally.

Acknowledgment. The authors extend their sincere thanks and appreciation to the Deanship of Scientific Research at King Saud University for funding this work through the Undergraduate Student's Research Support Program, Project No. (URSP-4-19-71). Also, the authors gratefully acknowledge Munerh Aldukhayil, Mohammed S. AlQhtani, Razan A. Alhamidi, Munirah A. Aldeghaim, and AlFahdah A. AlSaleem for their generous help with data collection and Dr. Riad Sulimani for reviewing the study questionnaire. We would also like to acknowledge Scribendi (https://www.scribendi.com) for English language editing.

\section{References}

1. Punjabi P, Hira A, Prasad S, Wang X, Chokhavatia S. Review of gastroesophageal reflux disease (GERD) in the diabetic patient. J Diabetes 2015; 7: 599-609.

2. Careyva B, Stello B. Diabetes mellitus: Management of gastrointestinal complications. Am Fam Physician 2016; 94 : 980-986.

3. Arora Z, Garber A, Thota PN. Risk factors for Barrett's esophagus. J Dig Dis 2016; 17: 215-221.

4. Lee SW, Lien HC, Lee TY, Yang SS, Yeh HJ, Chang CS. Heartburn and regurgitation have different impacts on life quality of patients with gastroesophageal reflux disease. World J Gastroenterol 2014; 20: 12277-12282.

5. Meo SA. Prevalence and future prediction of type 2 diabetes mellitus in the Kingdom of Saudi Arabia: A systematic review of published studies. J Pak Med Assoc 2016; 66: 722-725.

6. International Diabetes Federation. IDF Diabetes Atlas, 9th ed. Brussels, Belgium: 2019. [Updated 2020. Cited 2019 November 17 ]. Available from URL: http://www.diabetesatlas. org

7. Alsuwat OB, Alzahrani AA, Alzhrani MA, Alkhathami AM, Mahfouz ME. Prevalence of gastroesophageal reflux disease in Saudi Arabia. J Clin Med Res 2018; 10: 221-225.

8. Almadi MA, Almousa MA, Althwainy AF, Afnan M, Altamimi AM, Hala O, et al. Prevalence of symptoms of gastroesophageal reflux in a cohort of Saudi Arabians: a study of 1265 subjects. Saudi J Gastroenterol 2014; 20: 248-254.

9. Natalini J, Palit A, Sankineni A, Friedenberg FK. Diabetes mellitus is an independent risk for gastroesophageal reflux disease among urban African Americans. Dis Esophagus 2015; 28: 405-411.

10. Sun H, Yi L, Wu P, Li Y, Luo B, Xu S. Prevalence of gastroesophageal reflux disease in type II diabetes mellitus. Gastroenterol Res Pract 2014; 2014: 601571.

11. Jones R, Junghard O, Dent J, Vakil N, Halling K, Wernersson $\mathrm{B}$, et al. Development of the GerdQ, a tool for the diagnosis and management of gastro-oesophageal reflux disease in primary care. Aliment Pharmacol Ther 2009; 30: 1030-1038. 
12. Sağlan Y, Bilge U, Ünlüoğlu İ. Frequency of gastroesophageal reflux disease in patients with type 2 diabetes mellitus. Biomed Res 2017; Special Issue: S507-S512.

13. Sun XM, Tan JC, Zhu Y, Lin L. Association between diabetes mellitus and gastroesophageal reflux disease: A meta-analysis. World J Gastroenterol 2015; 21: 3085-3092.

14. Alkhathami AM, Alzahrani AA, Alzhrani MA, Alsuwat OB, Mahfouz MEM. Risk factors for gastroesophageal reflux disease in Saudi Arabia. Gastroenterol Res 2017; 10: 294-300.

15. Moradi-lakeh M, El Bcheraoui C, Tuffaha M, Daoud F, Saeedi M, Basulaiman M, et al. Tobacco consumption in the Kingdom of Saudi Arabia, 2013: findings from a national survey. BMC Public Health 2015; 15: 611.
16. Boronikolos GC, Menge BA, Schenker N, Breuer TG, Otte JM, Heckermann S, et al. Upper gastrointestinal motility and symptoms in individuals with diabetes, prediabetes and normal glucose tolerance. Diabetologia 2015; 58: 1175-1182.

17. Gokturk S, Akyuz F, Arici S, Alpaslan B, Ormeci A, Soyer $\mathrm{OM}$, et al. Gastroesophageal reflux in asymptomatic patients with diabetes: an impedance study diabetes, obesity and gastroesophageal reflux. Exp Clin Endocrinol Diabetes 2018; 128: 52-58.

18. Rouf MA, Khan M, Sharif JU, Karim MR, Rahman MM, Ahmed $\mathrm{H}$, et al. Prevalence of GERD in type II diabetes mellitus patients admitted in a Tertiary Care Hospital of Bangladesh. Mymensingh Med J 2017; 26: 710-715.

\section{Withdrawal policy}

By submission, the author grants the journal right of first publication. Therefore, the journal discourages unethical withdrawal of manuscript from the publication process after peer review. The corresponding author should send a formal request signed by all co-authors stating the reason for withdrawing the manuscript. Withdrawal of manuscript is only considered valid when the editor accepts, or approves the reason to withdraw the manuscript from publication. Subsequently, the author must receive a confirmation from the editorial office. Only at that stage, authors are free to submit the manuscript elsewhere.

No response from the authors to all journal communication after review and acceptance is also considered unethical withdrawal. Withdrawn manuscripts noted to have already been submitted or published in another journal will be subjected to sanctions in accordance with the journal policy. The journal will take disciplinary measures for unacceptable withdrawal of manuscripts. An embargo of 5 years will be enforced for the author and their co-authors, and their institute will be notified of this action. 